\title{
Contrasting patterns of isotype-1 $\beta$-tubulin allelic diversity in Haemonchus contortus and Haemonchus placei in the southern USA are consistent with a model of localised emergence of benzimidazole resistance
}

\author{
Umer Chaudhry $^{\mathrm{a}, \mathrm{b}, \mathrm{e}, *}$, E.M. Redman ${ }^{\mathrm{b}}$, Ray Kaplan ${ }^{\mathrm{c}}$, Thomas Yazwinski ${ }^{\mathrm{d}}$, Neil Sargison ${ }^{\mathrm{a}}$, John S. Gilleard ${ }^{\mathrm{b}, * *}$ \\ ${ }^{a}$ University of Edinburgh Royal (Dick) School of Veterinary Studies and Roslin Institute, Scotland, UK \\ ${ }^{\mathrm{b}}$ Department of Comparative Biology and Experimental Medicine, Faculty of Veterinary Medicine, University of Calgary Alberta, Canada \\ ${ }^{\mathrm{c}}$ Department of Infectious Diseases, College of Veterinary Medicine, University of Georgia, Athens, Georgia, USA \\ ${ }^{\mathrm{d}}$ Department of Animal Science, University of Arkansas, Fayetteville, Arkansas, USA \\ e Department of Veterinary Epidemiology and Public Health, School of Veterinary Medicine, University of Surrey, UK
}

\section{A R T I C L E I N F O}

Keywords

Haemonchus contortus

Haemonchus placei

benzimidazole resistance

isotype-1 $\beta$-tubulin

resistance emergence and spread

\begin{abstract}
A B S T R A C T
The benzimidazoles are one of the most important broad-spectrum anthelmintic drug classes for parasitic nematode control in domestic animals and humans. They have been widely used in livestock, particularly in small ruminants for over 40 years. This has resulted in widespread resistance in small ruminant gastrointestinal nematode parasite species, especially Haemonchus contortus. Benzimidazole resistance mutations have also been reported in Haemonchus placei, but only at low frequencies, suggesting resistance is a much earlier stage of emergence than is the case for $H$. contortus. Here, we investigate the haplotype diversity of isotype- $1 \beta$-tubulin benzimidazole resistance mutations and the population genetic structure of $H$. contortus and $H$. placei populations from sheep and cattle from the southern USA. Microsatellite genotyping revealed a low level of genetic differentiation in six H.placei and seven $H$. contortus populations examined. This is consistent with several previous studies from other regions, mainly in $H$. contortus, supporting a model of high gene flow between parasite populations. There was a single F200Y(TAC) haplotype present in all six $H$. placei populations across Georgia, Florida and Arkansas. In contrast, there were at least two different F200Y(T $\underline{\text { AC) }}$ ) haplotypes (up to four) and two different F167Y(T $\underline{\mathrm{AC}}$ ) haplotypes across the seven $H$. contortus populations studied. These results provide further evidence to support a model for benzimidazole resistance in Haemonchus spp, in which resistance mutations arise from a single, or the small number of locations, in a region during the early phases of emergence, and subsequently spread due to animal movement.
\end{abstract}

\section{Introduction}

Gastrointestinal nematode parasites are a major cause of disease in grazing ruminants, resulting in billions of US dollars of annual production loss in the livestock industry worldwide (Stromberg and Gasbarre, 2006). Anthelmintic resistance is an ever-increasing threat and understanding the patterns of its emergence is an important goal. Haemonchus contortus most commonly infects sheep and goats, causing significant economic losses worldwide, whereas Haemonchus placei predominantly infects large ruminants and its economic importance is generally restricted to warmer regions (Hoberg et al., 2004; Lichtenfels et al., 1994; Lichtenfels and Wergin, 1994). Benzimidazole resistance is at an advanced stage in $H$. contortus in many parts of the world and multiple studies have shown regional importance of single nucleotide polymorphisms (SNPs) at codons F167Y(TTC-TAC), E198A(GAA-GCA) and F200Y(TC-TAC) of the isotype-1 $\beta$-tubulin gene (Brasil et al., 2012; Ghisi et al., 2007; Hoglund et al., 2009; Kotze et al., 2012; Kwa et al., 1994; Redman et al., 2015; Rufener et al., 2009; Silvestre and Cabaret, 2002; Silvestre and Humbert, 2002). Although benzimidazole resistance is now emerging in $\mathrm{H}$. placei in cattle, it is generally at a much earlier stage than for $H$. contortus and is much less studied (Ali et al., 2019; Avramenko et al., 2020; Brasil et al., 2012). The F200Y(TAC) isotype-1 $\beta$-tubulin resistance mutations have been described in $H$. placei populations in the USA, Pakistan and Brazil (Ali et al., 2019; Avramenko et al., 2020; Brasil et al., 2012) and the F167Y(TAC) mutation has only been recorded in Brazil (Brasil et al., 2012).

\footnotetext{
* Corresponding author.

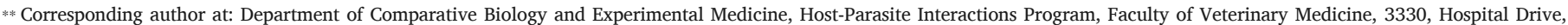
University of Calgary, Calgary, Alberta, T2N 4N1, Canada.

E-mail addresses: u.chaudhry@surrey.ac.uk (U. Chaudhry); jsgillea@ucalgary.ca (J.S. Gilleard)
} 
In the present study, we have compared the population genetic structure and the isotype- $1 \beta$-tubulin haplotype diversity of $H$. contortus and $H$. placei from sheep, goats and cattle sampled from the Arkansans, Florida and Georgia regions of the southern USA. For $H$. contortus, where resistance is at an advanced stage, we find multiple resistance haplotypes across the seven locations sampled. In contrast, for $H$. placei, where resistance is at an early stage of emergence, we find just a single resistance haplotype on all six locations surveyed. These results add to evidence from our previous work suggesting the importance of the spread of resistance from a single, or relatively small number of locations, during the early stages of its emergence.

\section{Materials and Methods}

\subsection{Parasite material}

Parasite material was obtained from three regions of the southern USA, where we anticipated a high prevalence of Haemonchus. Adult Haemonchus worms were harvested from the abomasa of 10 cattle, 2 sheep and 4 goats immediately following their slaughter at three different locations of Arkansas, Florida, and Georgia. Details of the 10 cattle parasite populations have been described in a previous report (Chaudhry et al., 2014). Briefly, three populations were obtained from Georgia (Pop86C, Pop87C, and Pop88C), one population from Florida (Pop85C) and six populations from Arkansas/Northeast Oklahoma (Pop9C, Pop67C, Pop76C, Pop80C, Pop81C, and Pop84C). In the case of Georgia, population Pop86C was collected from an animal pastured on a farm that also raised sheep, population Pop87C was from an animal on a farm where only cattle were pastured and a third population (Pop88C) was collected from an abattoir and so the grazing history was unknown. In the case of Arkansas, population Pop9C was collected from calves that were grazed on a single pasture at the University of Arkansas for 2 months before necropsy. Five populations (Pop67C, Pop76C, Pop80C, Pop81C and Pop84C) were collected from cattle purchased from a sale barn that were derived from different sources in Northwest Arkansas/Northeast Oklahoma and slaughtered immediately after purchase. A final population (Pop85C) was collected from a calf experimentally infected with $\mathrm{L}_{3}$ derived from several calves in Florida.

Two and three Haemonchus populations of sheep and goats, respectively, were collected from Arkansas (Pop1S, Pop2S, Pop10 G, Pop11 G, Pop12 G) and one goat-derived Haemonchus population was collected from Georgia (Pop1G). In the case of Arkansas, four populations (Pop2S, Pop10 G, Pop11 G, and Pop12 G) were collected directly from an abattoir, hence the host grazing history was unknown. The Pop1S population was collected from a farm, where sheep had been grazed on a single pasture for 6 months before necropsy. In the case of Georgia, population Pop1G was collected directly from the abattoir, with no grazing history.

Overall, the dataset was composed of 319 individual worms from 10 cattle, 64 individual worms from 2 sheep and 125 individual worms from 4 goats (Supplementary Table S1).

\section{2. gDNA extraction and pyrosequence genotyping}

Adult worms were fixed in $80 \%$ ethanol immediately following removal from the host abomasum. The heads of individual worms were dissected and lysed in a single 0.5 ul tube containing $40 \mu \mathrm{l}$ of lysis buffer and stored at $-80{ }^{\circ} \mathrm{C}$ as previously described by Chaudhry et al. (2016). $1 \mu \mathrm{l}$ of neat single worm lysate was used as a PCR template and identical dilutions of lysis buffer, made in parallel, were used as negative controls. To prepare pooled lysates of each population, $1 \mu \mathrm{l}$ aliquots of individual neat adult worm lysate were pooled, and $1 \mu \mathrm{l}$ was used as a PCR template. Pyrosequence genotyping of 10 cattle, 2 sheep and 4 goat derived lysates was performed to target the rDNA ITS- 2 and

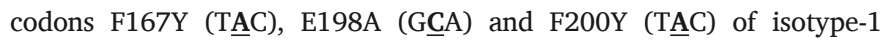
$\beta$-tubulin of $H$. placei and $H$. contortus was described in our previous studies (Chaudhry et al., 2014; Chaudhry et al., 2015b).

\subsection{Microsatellite genotyping}

Six previously published microsatellites (Hcms3561, Hcms53265, Hpms43, Hpms52, Hpms53, Hpms102) were selected as potentially useful markers based on our previous data (Chaudhry et al., 2015a; Chaudhry et al., 2016; Santos et al., 2017). These studies produced clear unambiguous genotypes with either a single or double Genescan peaks on single worms, as anticipated for single copy markers in both $H$. placei and $H$. contortus. Individual worm genotyping was performed from $6 \mathrm{H}$. placei populations (Pop76C, Pop9C, Pop80C, Pop85C, Pop88C, Pop87C) and $4 \mathrm{H}$. contortus populations (Pop1G, Pop10 G, Pop11 G, Pop12 G) that contained the F200Y(TAC) and F167Y(TAC) resistance-associated SNPs. A summary of primer sequences, allele ranges, PCR amplification, and bioinformatic analysis was described in our previous studies (Chaudhry et al., 2016; Santos et al., 2017).

\subsection{Phylogenetic analysis of the isotype-1 $\beta$-tubulin locus}

For the isotype- $1 \beta$-tubulin gene, a fragment encompassing parts of exons 4 and 5, including codons F167Y(TTC-TAC), E198A(GAA-GCA) and F200Y(TTC-TAC), for $H$. placei (325bp) and $H$. contortus (328bp) were amplified. Pooled lysates were made from $6 \mathrm{H}$. placei populations (Pop9C, Pop76C, Pop80C, Pop87C, Pop88C, Pop85C), in which F200Y (TAC) was detected and $7 \mathrm{H}$. contortus populations (Pop1S, Pop2S, Pop10 G, Pop11 G, Pop12 G, Pop1G, Pop86C) in which F200Y(TAC) and F167Y(TAC) were detected. Amplicons were cloned into PJET 1.2/ BLUNT vector (Thermo Scientific) and sequenced using standard procedures were described by Chaudhry et al. (2015b). For the phylogenetic analysis, sequences were aligned with $H$. placei and $H$. contortus isotype-1 $\beta$-tubulin reference sequences (Acc No KJ598498, Acc. No. $\times 67489$ ) and edited using Geneious Pro 5.4 software (Drummond et al., 2012). A previously described approach was used to filter the isotype-1 $\beta$-tubulin sequences to remove SNPs occurring only once in the dataset and ensure PCR-induced mutations were not included in the analysis (Chaudhry et al., 2015a; Chaudhry et al., 2016; Redman et al., 2015). The aligned sequences were then imported into the CD-HIT software (Huang et al., 2010) to calculate the number of unique haplotypes present in each population (Table 4). Construction of a network tree of the isotype- $1 \beta$-tubulin haplotypes was performed as described in our previous studies (Chaudhry et al., 2015a; Chaudhry et al., 2016).

\section{Results}

\subsection{Confirmation of $H$. placei and $H$. contortus species}

In our previous study, ITS-2 rDNA pyrosequence genotyping identified Haemonchus populations in 7 out of the 10 cattle hosts as comprising of $100 \%$ H. placei (P24; $\underline{\mathrm{G}}$ genotype), one population (Pop86C from Georgia) comprising of $100 \% H$. contortus (P24 A genotype), one population (Pop9C) comprising 97\% H. contortus (P24 A genotype) and 3\% H. placei (P24; $\underline{\mathrm{G}}$ genotype) and one population (Pop85C) comprising of $100 \%$ H. placei (P24; $\mathbf{G}$ genotype) except for a single worm with a heterozygous $\underline{\mathbf{A}} / \underline{\mathrm{G}}$ at position $\mathrm{P} 24$, suggesting that it may be a $\mathrm{H}$. placei / $\mathrm{H}$. contortus hybrid (Supplementary Table S1 \& Fig. 1) (Chaudhry et al., 2014). In the present study, between 29 and 32 individual Haemonchus worms were pyrosequence genotyped for the rDNA ITS-2 P24 SNP (64 worms form sheep and 125 worms from goats) and all worms identified as $H$. contortus (P24 A genotype) (Supplementary Table S1 \& Fig. 1). 


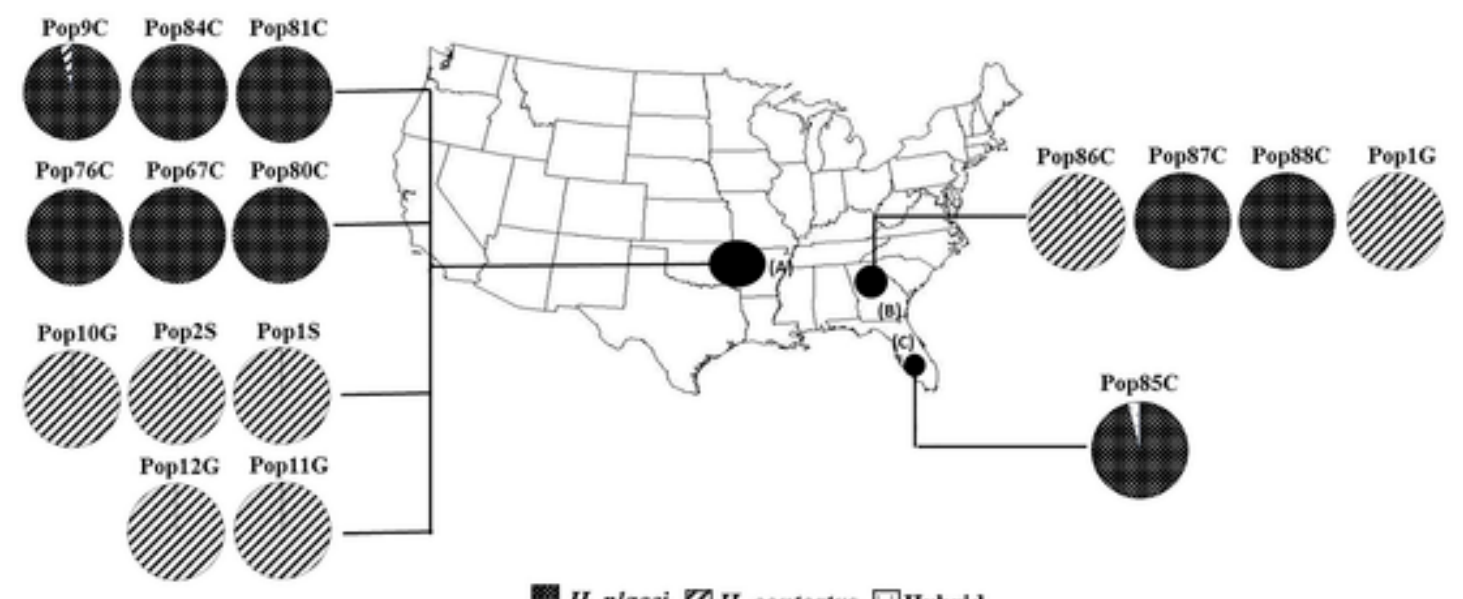

H. placei $\square$ H contortus $\mathrm{B}$ Hybrid

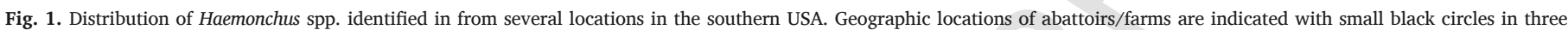

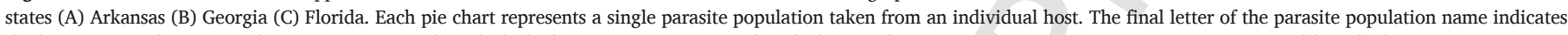

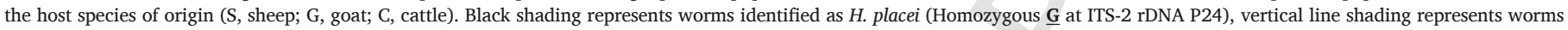
identified as $\mathrm{H}$. contortus (Homozygous $\underline{\mathbf{A}}$ at ITS-2 rDNA position P24) and the light dot represents worms identified as putative hybrids (heterozygous $\underline{\mathbf{A} / \mathrm{G}}$ at ITS-2 rDNA P24).

\subsection{Allele frequencies of the F167Y, E198A, F200Y polymorphisms in the} $H$. placei and $H$. contortus isotype-1 $\beta$-tubulin locus

In our previous study, pyrosequence genotyping was applied to individual worms from the $9 \mathrm{H}$. placei populations to genotype the iso-

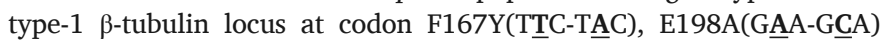
and F200Y(TTC-TAC). Six of the $9 \mathrm{H}$. placei populations contained the F200Y(TAC) benzimidazole resistance-associated SNP at low frequencies between 2-10\% (Supplementary Table S2) (Chaudhry et al., 2014). The benzimidazole resistance-associated F167Y(T므) and E198A(GCA) SNPs were not detected in any of these cattle populations. In the present study, pyrosequence genotyping was applied to the pooled worms from $7 \mathrm{H}$. contortus populations to genotype the isotype- $1 \beta$-tubulin locus

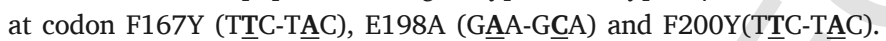
Benzimidazole resistance-associated SNPs were found in all 7 populations with the F200Y(TAC) mutation at high frequencies between $82-100 \%$ and 4 populations with the F167Y(TAC) mutation at low frequencies between 7-24\% (Supplementary Table S2). The benzimidazole resistance-associated SNP E198A(Gㅡㅅ) was not detected in any of the populations.

\subsection{Population genetic structure of $H$. placei and $H$. contortus}

Between 22 and 30 individual worms were successfully genotyped using a panel of six microsatellite markers for each of $6 \mathrm{H}$. placei and $4 \mathrm{H}$. contortus populations. To measure the level of genetic diversity between populations, the diversity index value was estimated. All populations were polymorphic at all loci, with the overall number of alleles per locus (A) ranging from 3 to 16 in $\mathrm{H}$. placei and 2 to 10 in $\mathrm{H}$. contortus respectively. Several unique alleles $\left(\mathrm{A}_{U}\right)$ were observed in each population (Table 1). There was some significant departure from Hardy-Weinberg equilibrium, even after Bonferroni correction, in 4 out of the 36 loci combinations for $H$. placei and 3 out of the 24 loci combinations for $H$. contortus, respectively (Table 1 ). There were no major departures from linkage equilibrium for any particular combination of loci across all populations indicating that alleles at these loci were randomly associated. $H$. placei and $H$. contortus showed a high level of overall genetic diversity in all populations, the mean allele richness $\left(\mathrm{A}_{\mathrm{C}}\right)$ was $7.750 \pm 0.603$ and $5.292 \pm 0.479$ respectively and expected heterozygosity $\left(\mathrm{H}_{\mathrm{e}}\right)$ was 0.705 (range: $0.042-0.701$ ) and 0.488 (range: 0.048-0.546) respectively (Table 1).
To measure the level of genetic difference between populations, the AMOVA and fixation index $\left(\mathrm{F}_{\mathrm{ST}}\right)$ value was estimated. The percentage of variation that partitioned between $6 \mathrm{H}$. placei populations was $0.042 \%$ and $4 \mathrm{H}$. contortus populations were $0.015 \%$. This was reflected by levels of pairwise $\mathrm{F}_{\mathrm{ST}}$ estimates with a maximum of 0.09 for 13 out of 15 possible pairwise comparisons in $H$. placei, and a maximum of 0.02 for 4 out of 6 possible pairwise comparisons in $H$. contortus, showing a low level of genetic differentiation (Table 2).

3.4. Haplotype distribution and the network analysis of isotype-1 $\beta$-tubulin locus of $H$. placei and $H$. contortus

A 325bp fragment of the isotype- $1 \beta$-tubulin locus was cloned and sequenced from the $6 \mathrm{H}$. placei populations containing the F200Y (TAC) SNP. The gDNA template was pooled from between 29 to 36 worms from each population (Supplementary Table S1) and between 6 and 12 clones were sequenced per population (Table 3). A single F200Y(TAC) resistance-conferring haplotype (Hr3 F200Y) was present in all six populations (Table 3; Fig. 2A) and five distinct susceptible haplotypes (designated Hs1, Hs2, Hs3, Hs4 and Hs5) were present across the six populations (Table 3, Fig. 2A). All haplotypes, except Hs4, were identified in more than one population supporting their validity (as opposed to PCR or sequencing artefacts). A phylogenetic haplotype network revealed that the single F200Y (TAC) resistance haplotype (Hr3 F200Y) was most closely related to the most frequent susceptible haplotype (Hs1) which was also present in all the six cattle populations (Fig. 3A).

A 328bp fragment of the isotype-1 $\beta$-tubulin locus was cloned and sequenced from $7 \mathrm{H}$. contortus populations. The gDNA template was pooled from between 29 to 32 worms from each population (Supplementary Table S1) and between 6 and 15 clones were sequenced per population (Table 3). A total of four $H$. contortus F200Y(TAC) resistance haplotypes (Hr12, Hr16, Hr22and Hr23) and two F167Y(TAC) resistance haplotypes (Hr20 and Hr29) were were identified in more than one population supporting their validity (Table 3; Fig. 2B), but no susceptible haplotypes were identified among 85 sequences of $7 \mathrm{H}$. contortus populations. A phylogenetic haplotype network was produced to examine the phylogenetic relationship between the six isotype-1 $\beta$-tubulin haplotypes (Fig. 3B). Hr12 was by far the most frequent and widely distributed haplotype, being identified in all 7 farms, followed by Hr29 (6 farms), and Hr23(2 farms) (Fig. 3B). Although Hr16, Hr22, and Hr20 haplotypes were at low frequency and only identified on a 
Table 1

Population genetic data for each microsatellite marker from six H. placei and four H. contortus populations based on panel of 6 microsatellite loci.

\begin{tabular}{|c|c|c|c|c|c|c|c|}
\hline Population & Hcms43 $\left(8^{\mathrm{b}}\right)$ & Hcms52 $\left(21^{\mathrm{b}}\right)$ & Hcms53 $\left(7^{\mathrm{b}}\right)$ & Hcms102 (14 $\left.{ }^{\mathrm{b}}\right)$ & Hcms3561 $\left(9^{b}\right)$ & Hcms5365 $\left(7^{\mathrm{b}}\right)$ & All loci \\
\hline \multicolumn{8}{|c|}{ Pop76C $\left(28^{a}\right)$} \\
\hline $\mathrm{N}_{\mathrm{o}}$ & 0 & 1 & 0 & 0 & 0 & 0 & \\
\hline$A_{U}$ & $7(0)$ & $15(1)$ & $6(0)$ & $11(1)$ & $6(0)$ & $3(0)$ & $49(2)$ \\
\hline $\mathrm{p}$-value & 0.0385 & 0.0477 & 0.3314 & 0.5550 & 0.0158 & 1.0000 & \\
\hline $\mathrm{H}_{\mathrm{e}}$ & 0.8103 & 0.9070 & 0.7896 & 0.8837 & 0.6662 & 0.1370 & 0.6990 \\
\hline $\mathrm{H}_{\mathrm{o}}$ & 0.7500 & 0.8148 & 0.8214 & 0.7857 & 0.3928 & 0.1428 & 0.6179 \\
\hline \multicolumn{8}{|c|}{ Pop9C $\left(22^{a}\right)$} \\
\hline $\mathrm{N}_{\mathrm{o}}$ & 0 & 2 & 0 & 0 & 0 & 0 & \\
\hline$A_{U}$ & $8(0)$ & $15(0)$ & $5(0)$ & $8(1)$ & $7(0)$ & $4(1)$ & $47(2)$ \\
\hline $\mathrm{p}$-value & 0.9528 & 0.1182 & 0.8642 & 0.4742 & 0.1571 & 1.0000 & \\
\hline $\mathrm{H}_{\mathrm{e}}$ & 0.7547 & 0.9346 & 0.7526 & 0.7896 & 0.7029 & 0.3583 & 0.7154 \\
\hline $\mathrm{H}_{\mathrm{O}}$ & 0.7727 & 0.9000 & 0.7727 & 0.7272 & 0.5454 & 0.4090 & 0.6878 \\
\hline \multicolumn{8}{|c|}{ Pop80C $\left(26^{a}\right)$} \\
\hline $\mathrm{N}_{\mathrm{o}}$ & 0 & 0 & 0 & 0 & 0 & 0 & \\
\hline$A_{U}$ & $7(0)$ & $13(1)$ & $4(0)$ & $10(0)$ & $4(0)$ & $3(0)$ & $41(1)$ \\
\hline $\mathrm{p}$-value & 0.5974 & 0.3985 & 0.3354 & 0.3262 & 0.0050 & 1.0000 & \\
\hline $\mathrm{H}_{\mathrm{e}}$ & 0.8137 & 0.9012 & 0.7096 & 0.8506 & 0.6289 & 0.3054 & 0.7016 \\
\hline $\mathrm{H}_{\mathrm{O}}$ & 0.7692 & 0.9230 & 0.6153 & 0.7692 & 0.4230 & 0.3461 & 0.6410 \\
\hline \multicolumn{8}{|c|}{ Pop85C $\left(31^{a}\right)$} \\
\hline $\mathrm{N}_{\mathrm{o}}$ & 0 & 0 & 0 & 0 & 0 & 1 & \\
\hline$A_{U}$ & $7(0)$ & $16(0)$ & $8(1)$ & $8(1)$ & $6(0)$ & $3(0)$ & $48(2)$ \\
\hline $\mathrm{p}$-value & 0.9687 & 0.3154 & 0.5429 & 0.3471 & 0.0076 & 0.1999 & \\
\hline $\mathrm{H}_{\mathrm{e}}$ & 0.7667 & 0.9360 & 0.7403 & 0.6266 & 0.6663 & 0.3406 & 0.6794 \\
\hline $\mathrm{H}_{\mathrm{o}}$ & 0.7096 & 0.9354 & 0.7741 & 0.8387 & 0.4838 & 0.2666 & 0.6681 \\
\hline \multicolumn{8}{|c|}{ Pop88C $\left(27^{a}\right)$} \\
\hline $\mathrm{N}_{\mathrm{O}}$ & 0 & 1 & 0 & 0 & 0 & 0 & \\
\hline$A_{U}$ & $8(0)$ & $16(0)$ & $7(0)$ & $7(1)$ & $7(0)$ & $5(1)$ & $50(2)$ \\
\hline p-value & 0.2362 & 0.6290 & 0.9341 & 0.1066 & 0.0013 & 1.0000 & \\
\hline $\mathrm{H}_{\mathrm{e}}$ & 0.7232 & 0.9027 & 0.7526 & 0.3053 & 0.7302 & 0.1775 & 0.5986 \\
\hline $\mathrm{H}_{\mathrm{O}}$ & 0.8148 & 0.8846 & 0.7777 & 0.2222 & 0.4074 & 0.1851 & 0.5486 \\
\hline \multicolumn{8}{|c|}{ Pop87C $\left(30^{a}\right)$} \\
\hline $\mathrm{N}_{\mathrm{o}}$ & 0 & 0 & 2 & 1 & 0 & 0 & \\
\hline $\mathrm{A}_{\mathrm{U}}$ & $6(0)$ & $13(0)$ & $4(0)$ & $10(0)$ & $4(0)$ & $5(1)$ & $42(1)$ \\
\hline p-value & 0.4166 & 0.3893 & 0.2677 & 0.0608 & 0.0000 & 1.0000 & \\
\hline $\mathrm{H}_{\mathrm{e}}$ & 0.7565 & 0.8977 & 0.7337 & 0.8663 & 0.6655 & 0.2552 & 0.6958 \\
\hline $\mathrm{H}_{\mathrm{o}}$ & 0.7333 & 0.9666 & 0.6785 & 0.6896 & 0.3333 & 0.2758 & 0.6129 \\
\hline \multicolumn{8}{|c|}{ H. contortus } \\
\hline Population & $\operatorname{Hcms} 43\left(4^{b}\right)$ & Hcms52 $\left(14^{b}\right)$ & $\operatorname{Hcms} 53\left(5^{b}\right)$ & $\operatorname{Hcms102}\left(6^{b}\right)$ & $\operatorname{Hcms} 3561\left(5^{b}\right)$ & Hcms5365 $\left(11^{b}\right)$ & All loci \\
\hline \multicolumn{8}{|c|}{ Pop1G $\left(26^{a}\right)$} \\
\hline $\mathrm{N}_{\mathrm{o}}$ & 0 & 0 & 0 & 8 & 0 & 0 & \\
\hline$A_{U}$ & $2(1)$ & $9(2)$ & $5(0)$ & $2(1)$ & $3(0)$ & $6(0)$ & $27(4)$ \\
\hline p-value & 1.0000 & 0.0179 & 0.2264 & 1.0000 & 0.2083 & 0.17225 & \\
\hline $\mathrm{H}_{\mathrm{e}}$ & 0.0384 & 0.8106 & 0.6078 & 0.1079 & 0.4954 & 0.6040 & 0.4440 \\
\hline $\mathrm{H}_{\mathrm{o}}$ & 0.0384 & 0.5600 & 0.5769 & 0.1111 & 0.3846 & 0.4800 & 0.3585 \\
\hline \multicolumn{8}{|c|}{ Pop10 G $\left(26^{a}\right)$} \\
\hline $\mathrm{N}_{\mathrm{O}}$ & 0 & 0 & 0 & 0 & 0 & 0 & \\
\hline $\mathrm{A}_{\mathrm{U}}$ & $3(0)$ & $5(0)$ & $5(0)$ & $4(1)$ & $5(2)$ & $9(1)$ & $31(4)$ \\
\hline $\mathrm{p}$-value & 1.0000 & 0.1938 & 0.2735 & 0.1738 & 0.0562 & 0.1743 & \\
\hline $\mathrm{H}_{\mathrm{e}}$ & 0.1802 & 0.6757 & 0.5935 & 0.2149 & 0.4208 & 0.5799 & 0.4441 \\
\hline $\mathrm{H}_{\mathrm{o}}$ & 0.1923 & 0.6923 & 0.5000 & 0.1923 & 0.3461 & 0.5000 & 0.4038 \\
\hline \multicolumn{8}{|c|}{ Pop11 G $\left(28^{a}\right)$} \\
\hline $\mathrm{N}_{\mathrm{o}}$ & 0 & 0 & 0 & 0 & 0 & 0 & \\
\hline$A_{U}$ & $3(0)$ & $10(2)$ & $5(0)$ & $3(0)$ & $3(0)$ & $8(0)$ & $32(2)$ \\
\hline p-value & 1.000 & 0.6746 & 0.7149 & 0.8480 & 0.0960 & 0.1587 & \\
\hline $\mathrm{H}_{\mathrm{e}}$ & 0.1370 & 0.8097 & 0.6039 & 0.4694 & 0.4642 & 0.7961 & 0.5467 \\
\hline $\mathrm{H}_{\mathrm{o}}$ & 0.1428 & 0.8214 & 0.6428 & 0.4285 & 0.3571 & 0.8214 & 0.5357 \\
\hline \multicolumn{8}{|c|}{ Pop12 G $\left(29^{a}\right)$} \\
\hline $\mathrm{N}_{\mathrm{o}}$ & 0 & 0 & 0 & 0 & 1 & 0 & \\
\hline$A_{U}$ & $3(0)$ & $8(0)$ & $5(0)$ & $4(0)$ & $3(0)$ & $7(1)$ & $30(1)$ \\
\hline $\mathrm{p}$-value & 1.0000 & 0.2343 & 0.9197 & 0.6122 & 0.0734 & 0.3337 & \\
\hline
\end{tabular}




\begin{tabular}{|c|c|c|c|c|c|c|c|}
\hline \multicolumn{8}{|l|}{ H. placei } \\
\hline Population & Hcms43 $\left(8^{\mathrm{b}}\right)$ & Hcms52 (21 $\left.{ }^{\mathrm{b}}\right)$ & $\operatorname{Hcms} 53\left(7^{\mathrm{b}}\right)$ & Hcms102 (14 $\left.{ }^{b}\right)$ & Hcms3561 $\left(9^{b}\right)$ & Hcms5365 $\left(7^{\mathrm{b}}\right)$ & All loci \\
\hline $\mathrm{H}_{\mathrm{e}}$ & 0.2266 & 0.6824 & 0.6474 & 0.3720 & 0.3221 & 0.5850 & 0.4726 \\
\hline $\mathrm{H}_{\mathrm{o}}$ & 0.2500 & 0.5714 & 0.6428 & 0.3928 & 0.2222 & 0.4642 & 0.4239 \\
\hline
\end{tabular}

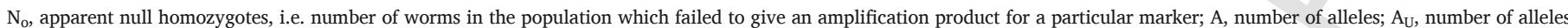

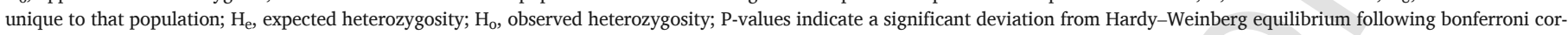
rection.

a Total number of individuals genotyped for each population is given in parenthesis under the population name.

b Total number of alleles for each marker across all populations is given in parenthesis below each marker name.

Table 2

Pairwise $\mathrm{F}_{\mathrm{ST}}$ comparison between the six $H$. placei and four $H$. contortus populations from three different geographical locations in Southern USA using six distinct microsatellite markers.

\begin{tabular}{|c|c|c|c|c|c|}
\hline \multicolumn{6}{|l|}{ H. placei } \\
\hline & Pop76C & Pop9C & Pop80C & Pop85C & Pop88C \\
\hline Рop9C & $\underline{0.02089}$ & & & & \\
\hline Pop80C & 0.00735 & $\underline{0.01853}$ & & & \\
\hline Pop85C & $\underline{0.05024}$ & 0.00284 & $\underline{0.04111}$ & & \\
\hline Pop88C & $\underline{0.09582}$ & $\underline{0.06766}$ & $\underline{0.09652}$ & $\underline{0.04451}$ & \\
\hline Pop87C & $\underline{0.02994}$ & $\underline{0.02087}$ & $\underline{0.02781}$ & $\underline{0.02669}$ & $\underline{0.06586}$ \\
\hline \multicolumn{6}{|c|}{ H. contortus } \\
\hline & \multicolumn{2}{|c|}{ Pop1G } & Pop10G & \multicolumn{2}{|c|}{ Pop11G } \\
\hline Pop10G & \multicolumn{2}{|c|}{$\underline{0.01716}$} & & \multirow{3}{*}{\multicolumn{2}{|c|}{0.01612}} \\
\hline Pop11G & \multicolumn{2}{|c|}{$\overline{0.02304}$} & 0.01082 & & \\
\hline Pop12G & \multicolumn{2}{|c|}{$\underline{0.02529}$} & 0.00273 & & \\
\hline
\end{tabular}

single farm each, they differed from the other haplotypes by multiple substitutions making them, more likely to be valid haplotypes rather than the result of PCR-induced mutation or sequencing error (Fig. 3B).

\section{Discussion}

Benzimidazole drugs have been intensively used in small ruminants worldwide for over 40 years leading to the development of resistance in multiple gastrointestinal nematode species including $H$. contortus. In the USA, most $H$. contortus populations in sheep and goats have extremely high levels of benzimidazole resistance (Kaplan and Vidyashankar, 2012). In the case of cattle in the USA, benzimidazoles have not been heavily used due to the predominance of macrocyclic lactone use in parasite control. Although there have been no published studies conclusively demonstrating phenotypic benzimidazole resistance in $\mathrm{H}$. placei in North America, benzimidazole resistance mutations have been reported by Chaudhry et al. (2014) and Avramenko et al. (2020). Indeed, despite the relatively limited use of benzimidazoles in USA beef cattle, the codon F200Y(TAC) mutation appears to be already widespread being detected in 6 out of $9 \mathrm{H}$. placei populations examined from Georgia, Arkansas and Florida (Chaudhry et al., 2014) and in 15 out of 32 H. placei populations examined from Oklahoma, Arkansas and Nebraska (Avramenko et al., 2020). However, this resistance mutation is at low frequencies in these populations $(1.6 \%-9.4 \%$ and $0.57-27.45 \%)$; these levels would not be expected to result in detectable loss of drug efficacy.

Table 3

The total number of sequences, resistant and susceptible isotype-1 $\beta$-tubulin haplotypes identified from six $H$. placei and seven $H$. contortus populations.

\begin{tabular}{|c|c|c|c|c|c|c|}
\hline $\begin{array}{l}\text { H. placei } \\
\text { populations }\end{array}$ & $\begin{array}{l}\text { No. of } \\
\text { Sequences }\end{array}$ & $\begin{array}{l}\text { F200Y (TAC) resistant haplotypes } \\
(\%)\end{array}$ & \multicolumn{3}{|c|}{ Susceptible haplotypes (\%) } & Total no of haplotypes \\
\hline Pop9C & 9 & Hr3 (11.11\%) & \multicolumn{3}{|c|}{ Hs1 (77.70\%), Hs2 (11.11\%) } & 3 \\
\hline Pop76C & 6 & Hr3 $(33.33 \%)$ & \multicolumn{3}{|c|}{ Hs1 (50\%), Hs2 (16.60\%) } & 3 \\
\hline Pop80C & 12 & Hr3 (16.66\%) & \multicolumn{3}{|c|}{ Hs1 (83.33\%) } & 2 \\
\hline Pop85C & 7 & Hr3 (14.20\%) & \multicolumn{3}{|c|}{ Hs1 (71.42\%), Hs4 (14.20\%) } & 3 \\
\hline Pop87C & 10 & $\mathrm{Hr} 3(50 \%)$ & \multicolumn{3}{|c|}{ Hs1 (10\%), Hs2 (20\%), Hs5 (20\%) } & 4 \\
\hline Pop88C & 9 & Hr3 (33.33\%) & \multicolumn{3}{|c|}{ Hs1 (22.22\%), Hs2 (11.11\%), Hs5 (22.22\%), Hs6 (11.11\%) } & \multirow[t]{2}{*}{5} \\
\hline $\mathrm{R}^{*}$ & 13 & $\operatorname{Hr} 3(25 \%)$ & & & & \\
\hline $\mathrm{S}^{*}$ & 39 & & \multicolumn{4}{|c|}{ Hs1 (53\%), Hs2 (9.60\%), Hs4 (1.90\%), Hs5 (7.60\%), Hs6 (1.92\%) } \\
\hline Total & 52 & 1 & 5 & & \multicolumn{2}{|r|}{6} \\
\hline $\begin{array}{l}\text { H. contortus } \\
\text { populations }\end{array}$ & $\begin{array}{l}\text { No. of } \\
\text { Sequences }\end{array}$ & F200Y (TAC) resistant haplotypes (\%) & & $\begin{array}{l}\text { F167Y (TAC) resistant } \\
\text { haplotypes }(\%)\end{array}$ & $\begin{array}{l}\text { Susceptible haplotypes } \\
(\%)\end{array}$ & $\begin{array}{l}\text { Total no of } \\
\text { haplotypes }\end{array}$ \\
\hline Pop1S & 13 & Hr12 (61.53\%), Hr22 (7.60\%), Hr23 (7.60\%) & & $\operatorname{Hr} 29(23.07 \%)$ & $0(0 \%)$ & 4 \\
\hline Pop2S & 9 & Hr12 (88.88\%) & & $\operatorname{Hr} 29(11.11 \%)$ & $0(0 \%)$ & 2 \\
\hline Pop10G & 15 & Hr12 (86.66\%), Hr23 (6.60\%) & & $\operatorname{Hr} 29(6.60 \%)$ & $0(0 \%)$ & 3 \\
\hline Pop11G & 14 & Hr12 $(92.80 \%)$ & & Hr29 (7.10\%) & $0(0 \%)$ & 2 \\
\hline Pop12G & 14 & $\operatorname{Hr} 12(92.80 \%)$ & & Hr29 (7.10\%) & $0(0 \%)$ & 2 \\
\hline Pop13G & 14 & Hr12 (92.85\%), Hr16 (7.14\%) & & $0(0 \%)$ & $0(0 \%)$ & 2 \\
\hline Pop86C & 6 & Hr12 (50\%) & & Hr20 (50\%) & $0(0 \%)$ & 2 \\
\hline $\mathrm{R}^{*}$ & 85 & $\begin{array}{l}\text { Hr12 (83.52\%), Hr16 (1.17\%), Hr22 (1.17\%), } \\
(2.30 \%)\end{array}$ & Hr23 & Hr29 (8.20\%), Hr20 (4. & & \\
\hline$S^{*}$ & 0 & & & & $0(0 \%)$ & \\
\hline Total & 85 & 4 & & 2 & & 6 \\
\hline
\end{tabular}

* Hr \& Hs indicated overall resistant and susceptible sequences and haplotypes in six H. placei and seven H. contortus populations. 
$\mathbf{A}$
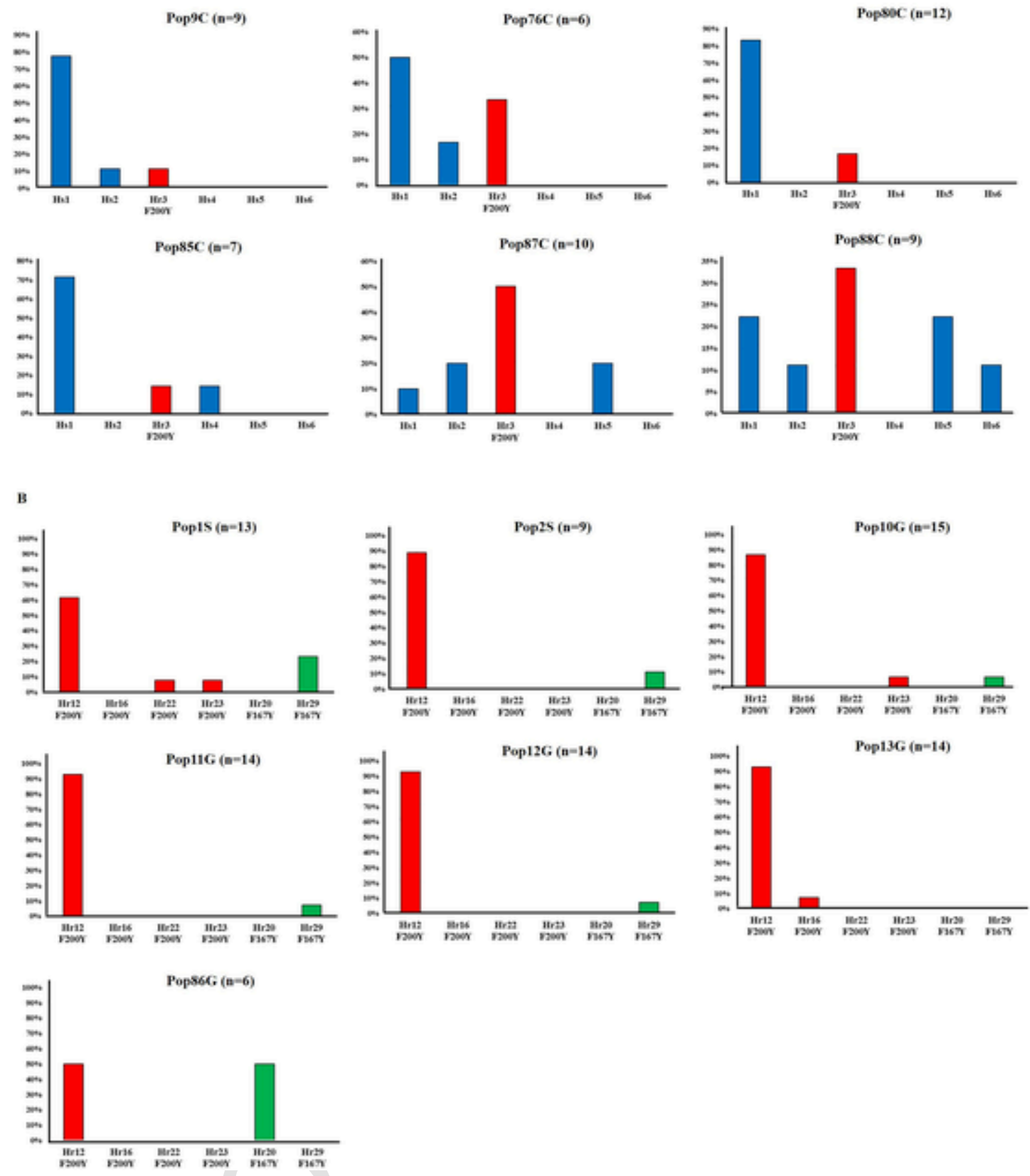

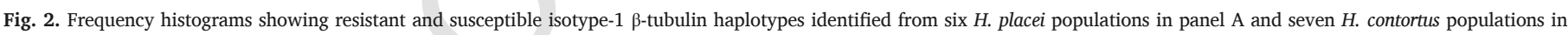

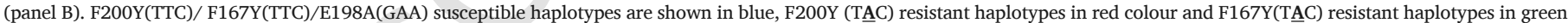
colour. The number of clones sequenced corresponding to each haplotype is shown above each bar (n).

This situation allows us to explore the patterns of resistance mutations relatively early and late stages of emergence in $H$. placei and $H$. contortus respectively. Our previous work in Pakistan, where there is a similar situation, clearly showed that the resistance was much lower in $H$. placei than in $H$. contortus (Ali et al., 2018). Indeed, the F200Y(TAC) mutation in $H$. placei was present on just a single haplotype in the multiple populations sampled, whereas the same mutation in $H$. contortus was present on up to 8 different haplotypes. The presence of just a single F200Y (TAC) haplotype in $H$. placei suggested to the spread of a resistance mutation from a single location during the early phases of resistance emergence (Ali et al., 2019). This built on our other previous work on the rarer E198A(GCA) mutation in H. contortus in India, where a similar pattern of haplotype diversity suggest- ing a single emergence of this mutation was found in the region (Chaudhry et al., 2015a).

The work presented in this paper was performed to further test the hypothesis that resistance spreads from a single, or a small number of locations, during the early phases of its emergence. We have found that for $H$. placei, where resistance is at a relatively early stage, there is just a single F200Y (TAC) haplotype (Hr3) in all 6 of the H. placei populations studied. The dominance of the Hs1 susceptible haplotype in the H. placei populations means there is insufficient susceptible allelic diversity to allow us to strongly conclude that the Hr3 haplotype is likely to have arisen just once in the region. However, the results are consistent with our previous work and provide further evidence for the genetic model that resistance mutations spread from a single, or a small number of locations in a region during the early phases (Ali et al., 


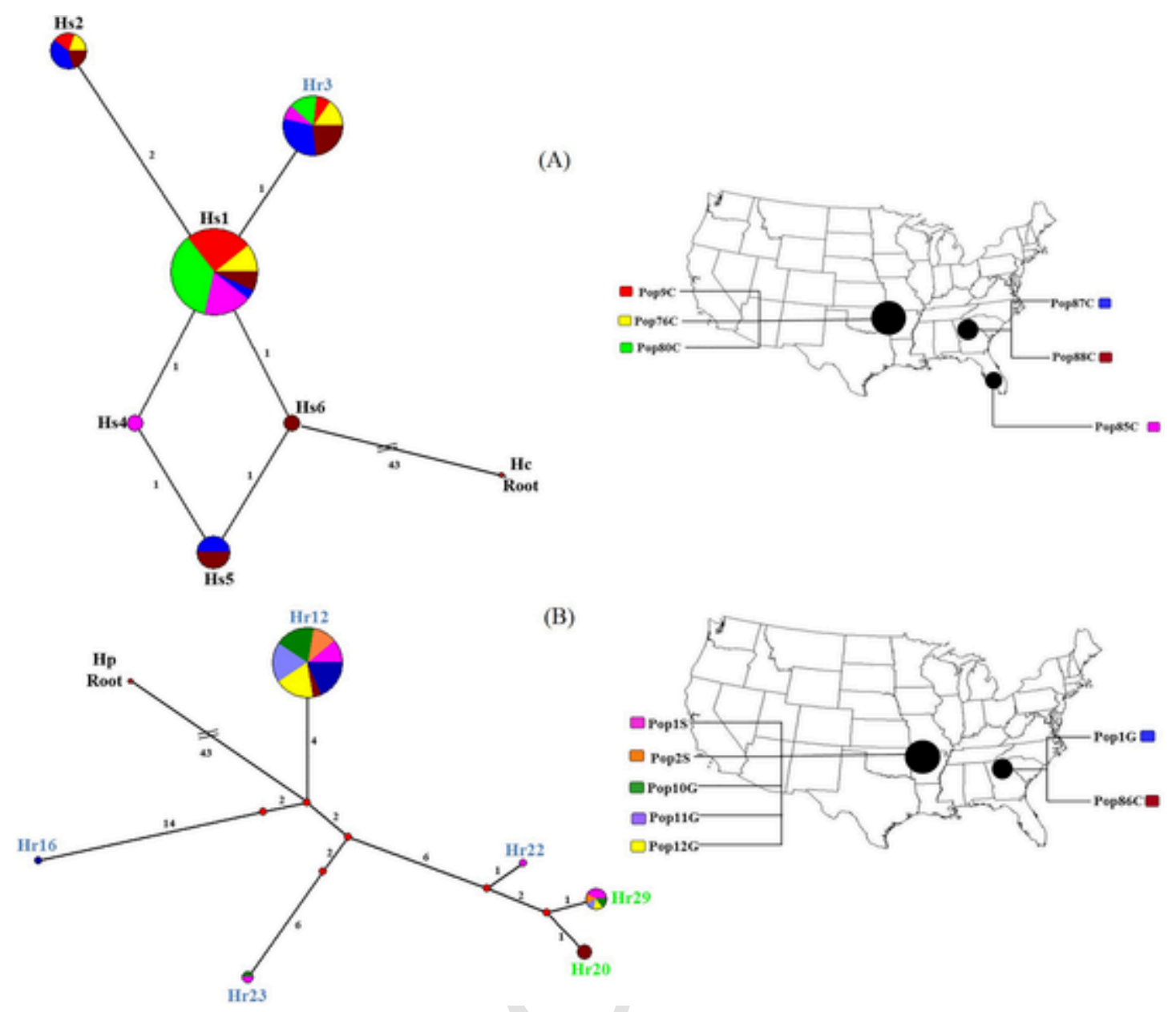

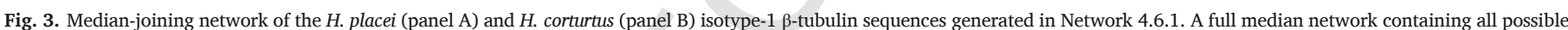

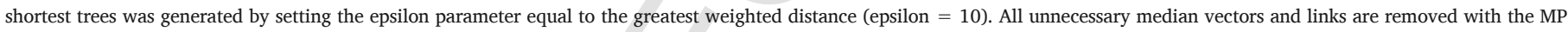

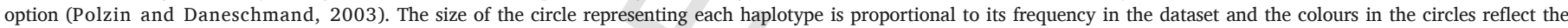

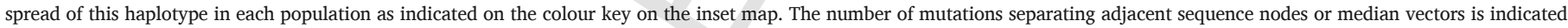

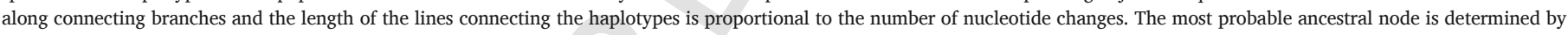

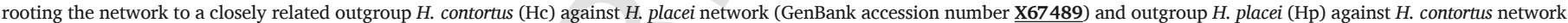

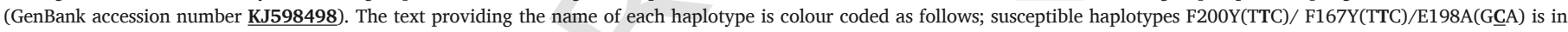
black text; F200Y(TAC) resistant haplotype is in blue text; F167Y(TAC) resistant haplotype is in green text.

2019; Chaudhry et al., 2015a). The $H$. placei results contrast with those of $H$. contortus, where resistance is more advanced since we identified at least two different F200Y(T스) (likely four) and two different F167Y(TAC) haplotypes across the $7 \mathrm{H}$. contortus populations sampled. The early spread of resistance from one or a small number of locations in a region emphasis the importance of livestock movement in the spread of benzimidazole resistance mutations in ruminants (Chaudhry et al., 2016).

There have been several studies on the population genetics of $H$. contortus but much less is known for $H$. placei (Chaudhry et al., 2015a; Chaudhry et al., 2016; Hunt et al., 2008; Redman et al., 2015; Silvestre et al., 2009). Microsatellite genotyping revealed a high level of genetic diversity among $H$. placei (allele richness $7.750 \pm 0.603$, expected heterozygosity 0.705 ) and $H$. contortus (allele richness $5.292 \pm 0.47$, expected heterozygosity 0.488 ) populations and a low level of genetic differentiation between the populations; $H$. placei $\left(\mathrm{F}_{\mathrm{st}}\right.$ estimates a maximum of 0.09 ) and $H$. contortus $\left(\mathrm{F}_{\mathrm{st}}\right.$ estimates a maximum of 0.02). This population genetic structure is consistent with that expected when high levels of gene flow occur between parasite populations and further supports the likelihood of the spread of resistance alleles in the southern USA.

\section{Declaration of Competing Interest}

The authors declare that they have no competing interests.

\section{Acknowledgements}

We would like to thank Natural Sciences and Engineering Research Council of Canada (NSERC) for funding support (Grant number RGPIN/ 371529-2209) as well as the NSERC-CREATE Host-Pathogen Interactions (HPI) graduate training program at the University of Calgary.

\section{Appendix A. Supplementary data}

Supplementary material related to this article can be found, in the online version, at doi:https://doi.org/10.1016/j.vetpar.2020.109240.

\section{References}

Ali, Q., Rashid, I., Shabbir, M.Z., Aziz Ul, R., Shahzad, K., Ashraf, K., Sargison, N.D., Chaudhry, U., 2019. Emergence and the spread of the F200Y benzimidazole resistance mutation in Haemonchus contortus and Haemonchus placei from buffalo and cattle. Vet. Parasitol. 265, 48-54.

Ali, Q., Rashid, I., Shabbir, M.Z., Shahzad, K., Ashraf, K., Sargison, N.D., Chaudhry, U., 2018. Population genetics of benzimidazole-resistant Haemonchus contortus and 
Haemonchus placei from buffalo and cattle: implications for the emergence and spread of resistance mutations. Parasitol. Res. 117, 3575-3583.

Avramenko, R.W., Redman, E.M., Windeyer, C., Gilleard, J.S., 2020. Assessing anthelmintic resistance risk in the post-genomic era: a proof-of-concept study assessing the potential for widespread benzimidazole-resistant gastrointestinal nematodes in North American cattle and bison. Parasitology 147, 897-906.

Brasil, B.S., Nunes, R.L., Bastianetto, E., Drummond, M.G., Carvalho, D.C., Leite, R.C., Molento, M.B., Oliveira, D.A., 2012. Genetic diversity patterns of Haemonchus placei and Haemonchus contortus populations isolated from domestic ruminants in Brazil. Int. J. Parasitol. 42, 469-479.

Chaudhry, U., Redman, E.M., Raman, Muthusamy, Gilleard, J.S., 2015. Genetic evidence for the spread of a benzimidazole resistance mutation across southern India from a single origin in the parasitic nematode Haemonchus contortus. Int. J. Parasitol. 15-00127-2.

Chaudhry, U., Miller, M., Yazwinski, T., Kaplan, R., Gilleard, J., 2014. The presence of benzimidazole resistance mutations in Haemonchus placei from US cattle. Vet. Parasitol. 204, 411-415.

Chaudhry, U., Redman, E., Abbas, M., Muthusamy, R., Ashraf, K., Gilleard, J., 2015. Genetic evidence for hybridisation between Haemonchus contortus and Haemonchus placei in natural field populations and its implications for interspecies transmission of anthelmintic resistance. Int. J. Parasitol. 45, 149-159.

Chaudhry, U., Redman, E.M., Ashraf, K., Shabbir, M.Z., Rashid, M.I., Ashraf, S., Gilleard, J.S., 2016. Microsatellite marker analysis of Haemonchus contortus populations from Pakistan suggests that frequent benzimidazole drug treatment does not result in a reduction of overall genetic diversity. Parasit. Vect. 9, 349.

Drummond, A.J., A.B., Buxton, S, Cheung, M, Cooper, A, Duran, C, Field, M, Heled, J, Kearse, M, Markowitz, S, Moir, R, Stones-Havas, S, Sturrock, S., Thierer, T, Wilson, A, 2012. Geneious v5.6.

Ghisi, M., Kaminsky, R., Maser, P., 2007. Phenotyping and genotyping of Haemonchus contortus isolates reveals a new putative candidate mutation for benzimidazole resistance in nematodes. Vet. Parasitol. 144, 313-320.

Hoberg, E.R., Lichtenfels, J.R., Gibbons, L., 2004. Phylogeny for species of Haemonchus (Nematoda: Trichostrongyloidea): considerations of their evolutionary history and global biogeography among Camelidae and Pecora (Artiodactyla). J. Parasitol. 90, $1085-1102$.

Hoglund, J., Gustafsson, K., Ljungstrom, B.L., Engstrom, A., Donnan, A., Skuce, P., 2009. Anthelmintic resistance in Swedish sheep flocks based on a comparison of the results from the faecal egg count reduction test and resistant allele frequencies of the beta-tubulin gene. Vet. Parasitol. 161, 60-68.

Huang, Y., Niu, B., Gao, Y., Fu, L., Li, W., 2010. CD-HIT Suite: a web server for clustering and comparing biological sequences. Bioinformatics 26, 680-682.
Hunt, P., Knox, M., Le Jambre, L., McNally, J., Anderson, L., 2008. Genetic and phenotypic differences between isolates of Haemonchus contortus in Australia. Int. J. Parasitol. 38, 885-900.

Kaplan, R.M., Vidyashankar, A.N., 2012. An inconvenient truth: global worming and anthelmintic resistance. Vet. Parasitol. 186, 70-78.

Kotze, A.C., Katie, Bagnall, Neil, Hines, Barney, Ruffell, Angela, Coleman, Glen, 2012. Relative level of thiabendazole resistance associated with the E198A and F200Y SNPs in larvae of a multi-drug resistant isolate of Haemonchus contortus. Int. J. Parasitol. 2, 92-97.

Kwa, M.S., Veenstra, J.G., Roos, M.H., 1994. Benzimidazole resistance in Haemonchus contortus is correlated with a conserved mutation at amino acid 200 in beta-tubulin isotype 1. Mol. Biochem. Parasitol. 63, 299-303.

Lichtenfels, J.R., Pilitt, P.A., Hoberg, E.P., 1994. New morphological characters for identifying individual specimens of Haemonchus spp. (Nematoda: Trichostrongyloidea) and a key to species in ruminants of North America. J. Parasitol. 80, 107-119.

Lichtenfels, J.R., Wergin, W., 1994. Sublateral hypodermal chords in Haemonchus (Nematoda: Trichostrongyloidea): description and potential as a systematic character. J. Parasitol. 80 (4), 620-624.

Polzin, T., Daneschmand, S.V., 2003. On Steiner trees and minimum spanning trees in hypergraphs. Oper. Res. Lett 31, 12-20.

Redman, E., Whitelaw, F., Tait, A., Burgess, C., Bartley, Y., Skuce, P., Jackson, F., Gilleard, J., 2015. The emergence of resistance to the benzimidazole anthlemintics in parasitic nematodes of livestock is characterised by multiple independent hard and soft selective sweeps. PLoS Negl. Trop. Dis. 6 (9), e0003494 doi:.

Rufener, L., Kaminsky, R., Maser, P., 2009. In vitro selection of Haemonchus contortus for benzimidazole resistance reveals a mutation at amino acid 198 of beta-tubulin. Mol. Biochem. Parasitol. 168, 120-122.

Santos, M.C., Redman, E., Amarante, M.R., Gilleard, J.S., Amarante, A.F., 2017. A panel of microsatellite markers to discriminate and study interactions between Haemonchus contortus and Haemonchus placei. Vet. Parasitol. 244, 71-75.

Silvestre, A., Cabaret, J., 2002. Mutation in position 167 of isotype 1 beta-tubulin gene of Trichostrongylid nematodes: role in benzimidazole resistance? Mol. Biochem. Parasitol. 120, 297-300.

Silvestre, A., Humbert, J.F., 2002. Diversity of benzimidazole-resistance alleles in populations of small ruminant parasites. Int. J. Parasitol. 32, 921-928.

Silvestre, A., Sauve, C., Cortet, J., Cabaret, J., 2009. Contrasting genetic structures of two parasitic nematodes, determined on the basis of neutral microsatellite markers and selected anthelmintic resistance markers. Mol. Ecol. 18, 5086-5100.

Stromberg, B.E., Gasbarre, L.C., 2006. Gastrointestinal nematode control programs with an emphasis on cattle. Vet. Clin. North. Am. Food. Anim. Pract. 22, 543-565. 